\title{
Converting $\mathrm{CoMoO}_{4}$ into $\mathrm{CoO} / \mathrm{MoO}_{\mathrm{x}}$ for overall water splitting by hydrogenation
}

Xiaodong Yan, ${ }^{\dagger}$ Lihong Tian, ${ }^{\dagger, l}$ Samuel Atkins, ${ }^{\dagger}$ Yan Liu,${ }^{\dagger, \perp}$ James Murowchick ${ }^{\ddagger}$ and Xiaobo Chen ${ }^{\dagger}, *$

†Department of Chemistry, University of Missouri - Kansas City, Kansas City, Missouri 64110, USA

'Hubei Collaborative Innovation Center for Advanced Organochemical Materials, Ministry-ofEducation Key Laboratory for the Synthesis and Applications of Organic Functional Molecules, Hubei University, Wuhan, Hubei 430062, China

${ }^{\perp}$ College of Environment, Sichuan Agricultural University, Chengdu, Sichuan 611130, China.

Department of Geosciences, University of Missouri - Kansas City, Kansas City, Missouri 64110, USA

* Corresponding author

E-mail address: chenxiaobo@umkc.edu

8 pages: page $\mathrm{S} 1-\mathrm{S} 8$

7 figures: Figure S1-S7 


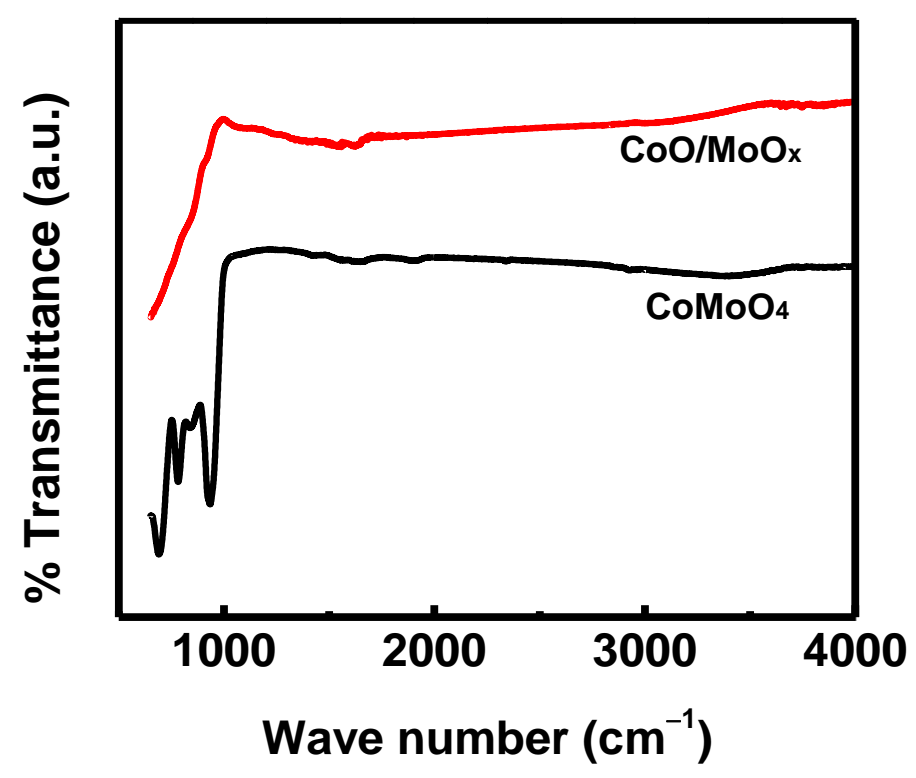

Figure S1 FTIR spectra of $\mathrm{CoMoO}_{4}$ and $\mathrm{CoO} / \mathrm{MoO}_{\mathrm{x}}$. 


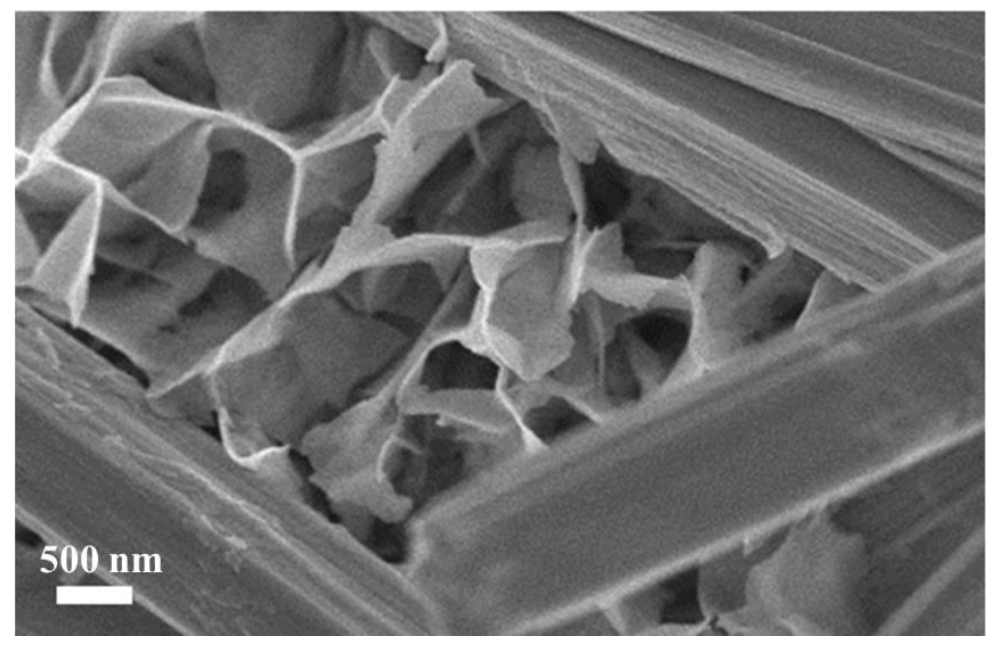

Figure S2 SEM image of $\mathrm{CoMoO}_{4}$. 


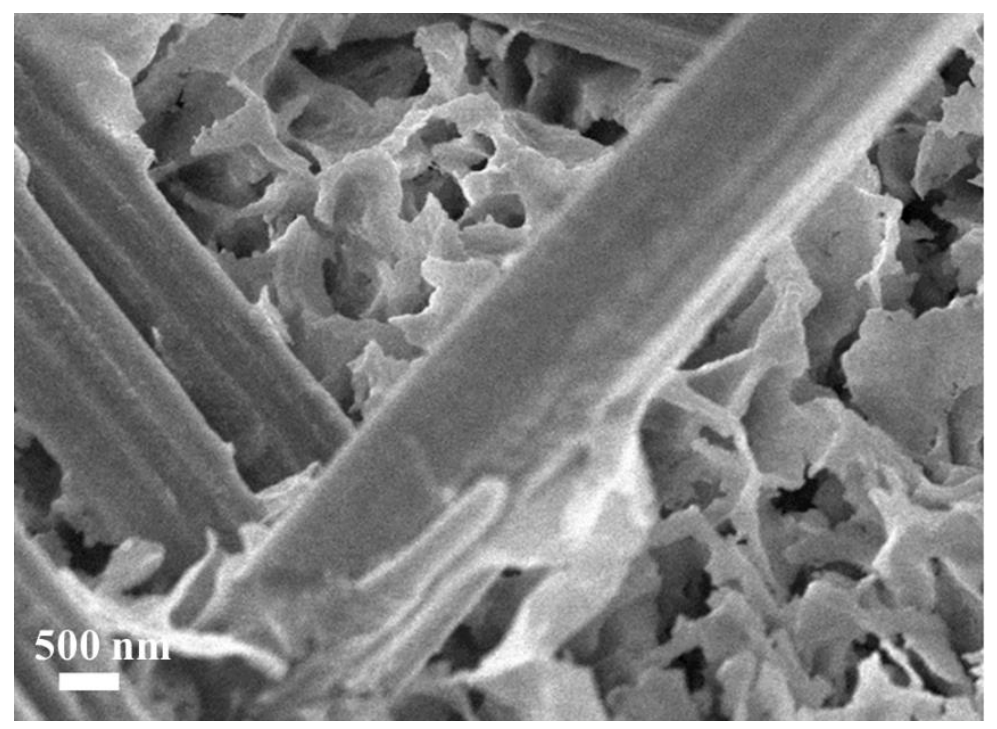

Figure S3 SEM image of $\mathrm{CoO} / \mathrm{MoO}_{\mathrm{x}}$. 

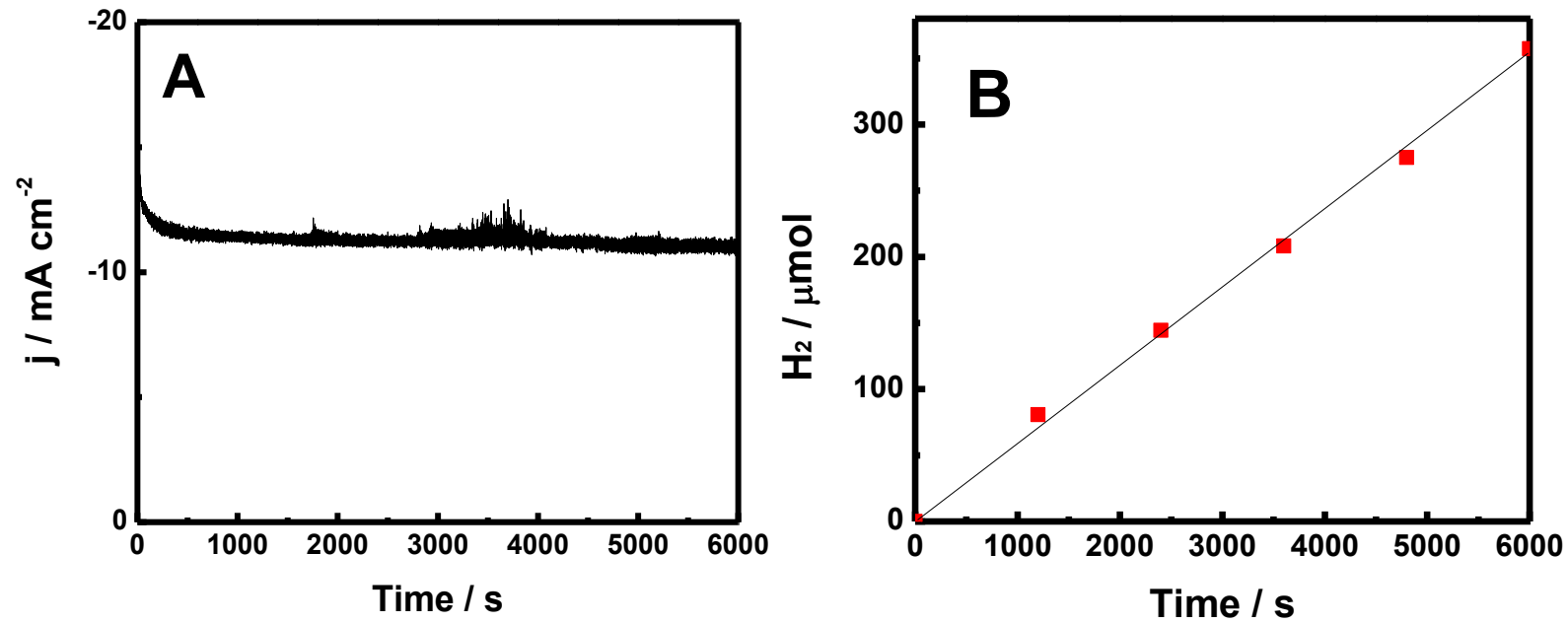

Figure S4. (A) Chronopotentiometry curve of $\mathrm{CoO} / \mathrm{MoO}_{\mathrm{x}}$ without iR-compensation, and (B) the corresponding $\mathrm{H}_{2}$ produced. 

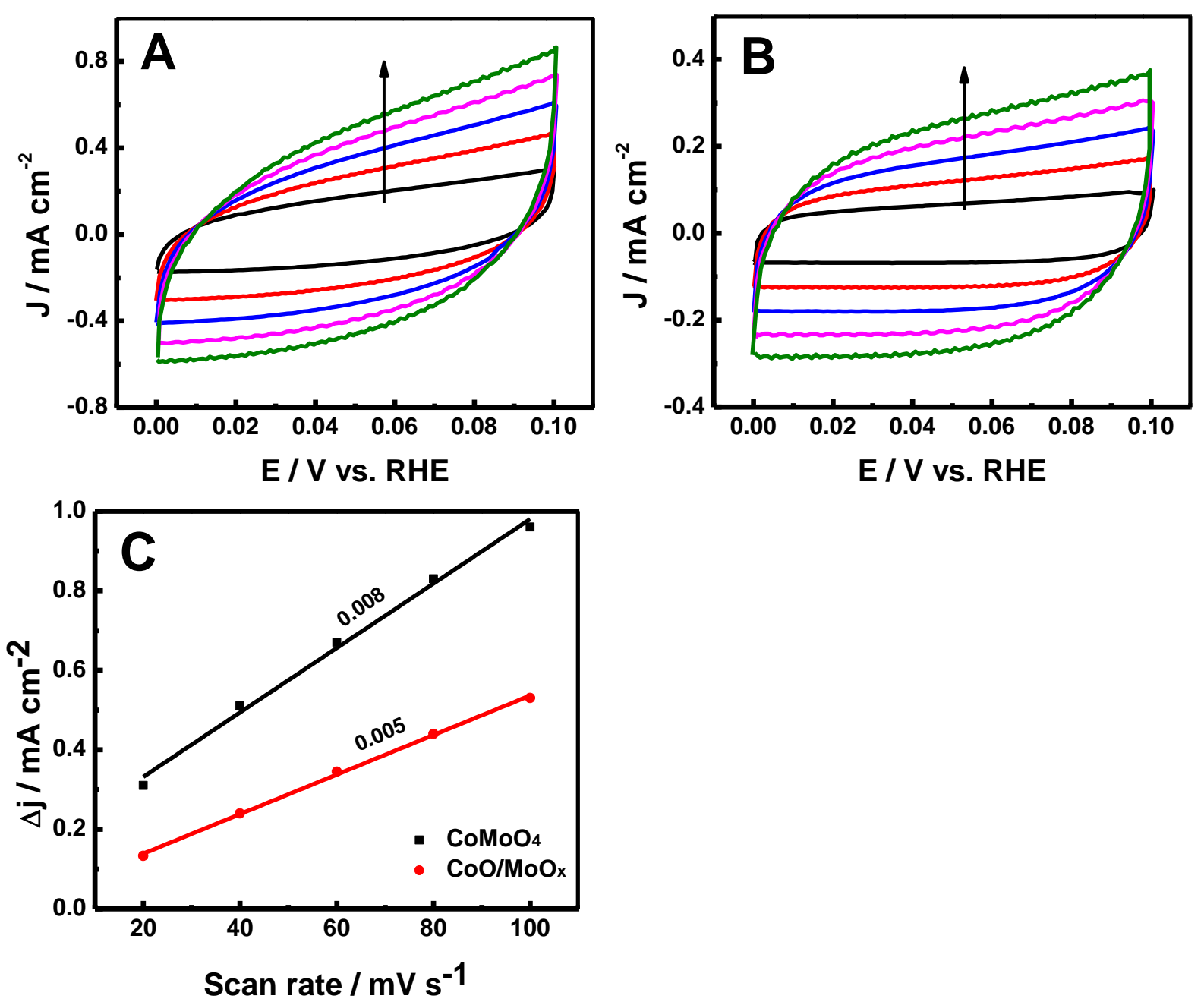

Figure S5. Cyclic voltammograms of (A) $\mathrm{CoMoO}_{4}$ and (B) $\mathrm{CoO} / \mathrm{MoO}_{\mathrm{x}}$ at various scan rates (20, 40, 60, 80 and $\left.100 \mathrm{mV} \mathrm{s}^{-1}\right)$. (C) Differences $\left(\Delta \mathrm{j}=\left(\mathrm{j}_{\mathrm{a}}-\mathrm{j}_{\mathrm{c}}\right)\right.$ in current density at $0.05 \mathrm{~V}$ vs RHE plotted against scan rate. 

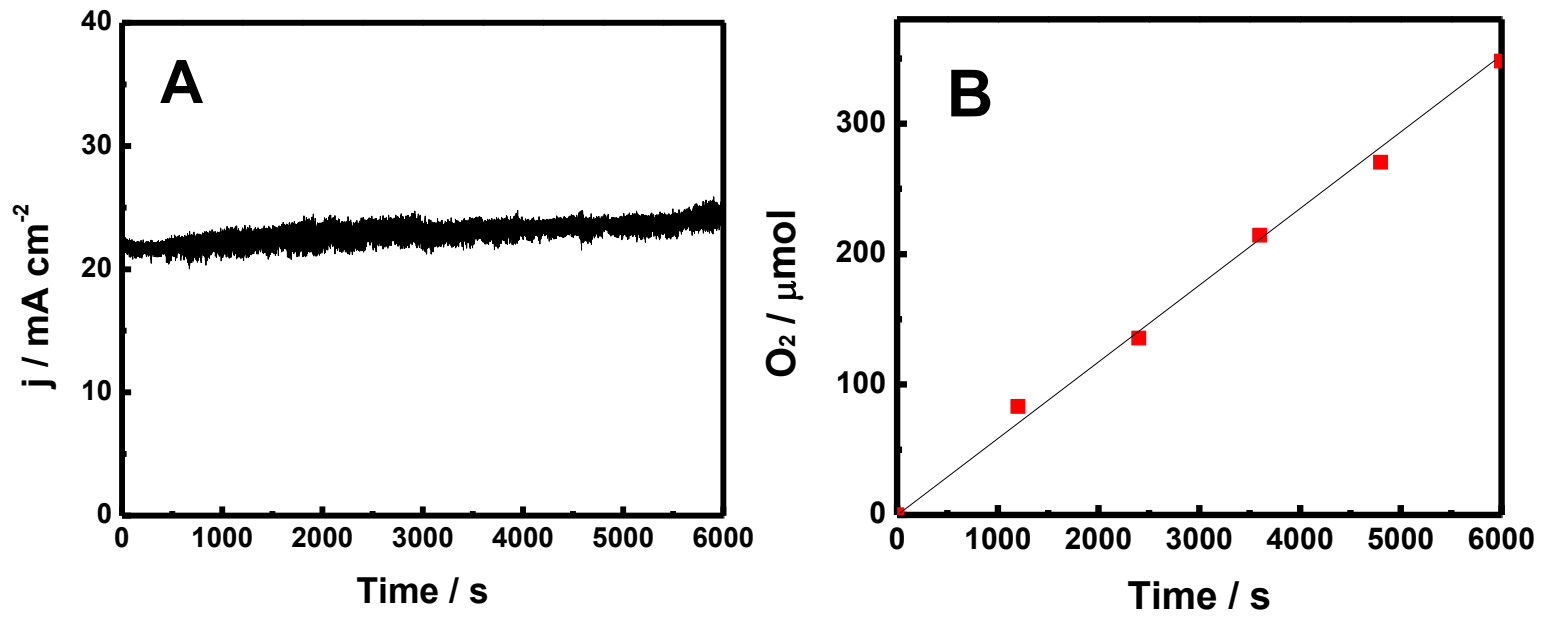

Figure S6. (A) Current-time characteristics of $\mathrm{CoO} / \mathrm{MoO}_{\mathrm{x}}$ at overpotential of $350 \mathrm{mV}$ without iRcompensation, and (B) the corresponding $\mathrm{O}_{2}$ produced. 

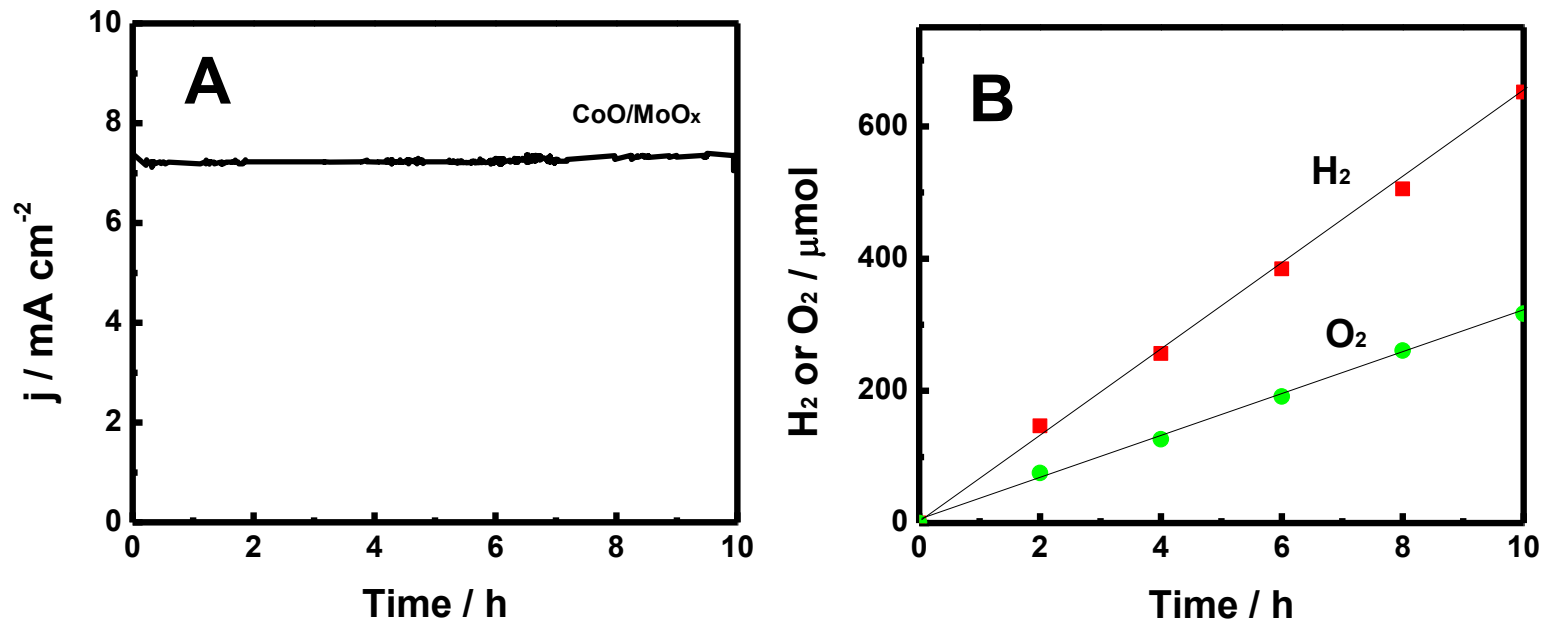

Figure S7. (A) The current-time characteristics at a voltage of $1.70 \mathrm{~V}$ for the overall water-splitting characteristics of the $\mathrm{CoO} / \mathrm{MoO}_{\mathrm{x}} \| \mathrm{CoO} / \mathrm{MoO}_{\mathrm{x}}$ in two-electrode configuration in $1 \mathrm{M} \mathrm{KOH}$. All the data are without $\mathrm{iR}$ compensation, and (B) the corresponding $\mathrm{H}_{2}$ and $\mathrm{O}_{2}$ produced. 